\title{
Migration and post-university transition. Why do university graduates not return to their rural home region?
}

\author{
Patrick Rérat \\ Institute of geography and sustainability, University of Lausanne, Mouline - Géopolis, \\ 1015 Lausanne, Switzerland \\ Correspondence to: Patrick Rérat (patrick.rerat@unil.ch)
}

Received: 25 March 2016 - Revised: 26 September 2016 - Accepted: 2 October 2016 - Published: 19 October 2016

\begin{abstract}
This paper addresses migrations taking place during the transition from higher education to the labour market. It analyses the reasons why graduates do not return to their rural home region after university, with a case study in Switzerland. Drawing on the mechanisms identified in the literature on internal migration, I propose to conceptualize migration choice as a combination of four logics: utilitarian (job opportunities), calculating (financial elements), affective (social and love life) and sensitive (residential amenities). The analysis of the motives reported by graduates indicates that migration decisions cannot be reduced to a single dimension (although job opportunities are central), are diverse (even within a homogeneous group) and depend on a variety of constraints.
\end{abstract}

\section{Introduction}

In many countries, a growing proportion of young adults are accessing higher education (HE). This has provoked an increase in education-based migration, as HE institutions are located in a limited number of places. These young adults experience various forms of mobility involved in attending HE institutions (e.g. moving to the university city or commuting) and later in the transition from HE to the labour market. The uneven geographies of graduates' moves have been highlighted in a wide range of contexts, and it has been acknowledged that peripheral and rural regions tend to lose graduates (see Corcoran et al., 2010; Haartsen and Thissen, 2014; Findlay et al., 2009; Smith and Sage, 2014).

Why do young graduates not return to their rural home region? The answer may seem obvious if we look at the work of earlier migration scholars like Ravenstein, who observed the importance of migration from rural to urban regions, the overrepresentation of young adults in such moves and the major weight of economic factors (Ravenstein, 1889). Graduate migration has also long been interpreted in terms of the characteristics of both origin and destination regions, in particular regarding their labour markets. Highly educated individuals are assumed to have much greater opportunities in the larger centres, in terms of employment and wage premiums (Glaeser and Maré, 2001). Are things really so clear, though? Scholars have argued that migration is not restricted to economic factors and that investigation is needed in order to fully understand the patterns and mechanisms (Fielding, 1992; Halfacree, 2004).

Drawing on this last argument, this paper addresses postuniversity migration based on a case study in Switzerland. It analyses the self-reported motives of young adults who do not return to their rural home region after graduation. The next section discusses perspectives in migration studies in order to conceptualize migration decisions as depending on a combination of and trade-offs between four logics: utilitarian, calculating, affective and sensitive. The following section presents the spatial context, the research design and the methodology. The final section discusses empirical results regarding graduates' migration flows and the motives they report. The conclusion then highlights the importance of combining both macro and micro scales of analysis and of regarding migration as the outcome of these four logics. 


\section{Theoretical discussion}

\subsection{Typologies of perspectives on migration}

Boyle et al. (1998) suggest two broad typologies in migration studies that also concern post-graduation internal migration. First, the macro perspective addresses migrations on an aggregate level and explains them in relation to the spatial context (differentials in the level of salaries or unemployment, etc.), while the micro-analytic perspective is centred on individuals. Second, "determinist" approaches "play down the role of the individual" and assume "migration to be an almost inevitable response to some rational situation" (Boyle et al., 1998:57), while humanist approaches consider migrants as individual actors who have a certain level of agency. The latter explain migration behaviours in the light of psychological factors such as aspirations and motivations. In other words, the focus is not on the objective characteristics of sending/receiving regions but on the actors' representations. This typology has some limitations and research may combine these approaches. It highlights nonetheless two major differentiation axes in migration studies: the scale (spaces vs. individuals) and the identification of motives (postulated by the researcher or self-reported by migrants).

The research on internal migration has been dominated by "determinist" approaches either through a macro lens (e.g. flows between regions explained mainly by sociocultural and economic determinants) or a micro lens (e.g. individuals' characteristics and migration behaviour taken from panel surveys and modelled with logistic regressions). While many of these studies adopt microeconomic principles, where the migrant is seen as economically rational, some others have indirectly taken into account non-deterministic factors. These econometric analyses have notably identified the impact on migration of variables such as gender, ethnicity, field of study, sense of belonging, etc. (see Faggian et al., 2006; Corcoran et al., 2010) and the differences between return and non-return migrants (DaVanzo, 1976).

However, these approaches do not usually include information on motivations and decision processes as stated by migrants themselves, whereas several debates in mobility studies show the importance of directly addressing the points of view of actors in order to fully understand their logics. Three main reasons back up this argument: the complexity of motivations, the diversity of migration behaviours and the existence of alternative strategies to migration.

First, determinist approaches apply pre-defined behaviour to migrants and take for granted that their migration decision is (economically) rational and/or determined by economic restructuring. They may fail to reflect the complex decisionmaking process of migrants and to interpret what a given structural factor means to them (Niedomysl and Hansen, 2010). The complexity of the migration decision has actually been recognized, acknowledging it to be based on a variety of motives and not only on economic ones. Fielding (1992), for example, calls for an approach to internal migration that goes "beyond the economic", and Halfacree (2004:239) highlights the need to show greater appreciation of the "non-economic" issues of migration behaviour, balancing rather than replacing work done within the economic tradition. In the case of post-university migration, Smith et al. (2014:3) argue for a structurationist reading. They state that moves are a "response to changing opportunities and constraints triggered by dynamic, structural conditions" (the education system, for example) and pose questions about "the capacity and power of young migrant agency to create/reproduce, and become embroiled in both new and traditional forms of youth migration".

Second, individualization theories argue that contemporary societies are characterized by their "disembedding" from traditional social constraints. Beck (1992) speaks of "do-it-yourself biographies" in reference to the level of choice now available to the contemporary individual. The transitions from childhood to adulthood stretch over an intermediary period of "youth" (Jeffrey, 2010) with many potential changes to personal, professional and residential status. Young people's trajectories are more diverse, and staying in their home region is one of many options (Haartsen and Thissen, 2014).

Third, some works stress the agency of migrants, who are not merely subjected to external forces (Lundholm, 2010). The employment-migration nexus has to be rethought in a context of changing mobility opportunities. This echoes what Zelinsky (1971) anticipated in his model of mobility transition: with the development of transport infrastructures, some forms of migration are replaced by circulation. In other words, some people - including some young adults entering the labour market with short-term contracts - may decide to make the most of transport infrastructures to commute over long distances, avoiding migration (Vincent-Geslin and Kaufmann, 2012) ${ }^{1}$.

\subsection{Conceptualizing migration motivations}

As shown by Lahire (2010), each person inevitably carries a plurality of roles and ways of seeing, feeling and acting. Dubet (1994) states that actors relate to several rationalities that cannot be reduced to the paradigm of a pure theory. According to pragmatic sociology, actions are motivated, legitimated and evaluated by several coexisting principles or "registers of action" resulting from the actors' values and interests (Boltanski and Thévenot, 2006). Drawing on the work on housing choice by Pattaroni et al. (2009), in this study I apply this approach to the internal migration of young graduates in their transition to the labour market. I argue that gradu-

\footnotetext{
${ }^{1}$ In Switzerland, the proportion of long-distance commuters has increased, while migration between cantons has declined (Schuler et al., 2007). This corroborates the substitution over time between commuting and migration.
} 
Table 1. Logics of internal migration.

\begin{tabular}{|c|c|c|}
\hline Logics & Factors & Examples of dimensions \\
\hline Utilitarian & $\begin{array}{l}\text { Factors related } \\
\text { to } \\
\text { the labour market }\end{array}$ & $\begin{array}{l}\text { Job opportunities } \\
\text { Future career perspectives }\end{array}$ \\
\hline Calculating & $\begin{array}{l}\text { Factors of } \\
\text { financial nature }\end{array}$ & $\begin{array}{l}\text { Level of salary } \\
\text { Tax rates } \\
\text { Housing prices }\end{array}$ \\
\hline Affective & $\begin{array}{l}\text { Factors related } \\
\text { to } \\
\text { social life }\end{array}$ & $\begin{array}{l}\text { Partner } \\
\text { Circle of friends/family members } \\
\text { Clubs and societies (social activities) } \\
\text { Desire for change }\end{array}$ \\
\hline Sensitive & $\begin{array}{l}\text { Factors related } \\
\text { to } \\
\text { residential } \\
\text { amenities }\end{array}$ & $\begin{array}{l}\text { Life setting and amenities } \\
\text { Cultural and leisure offerings } \\
\text { Urban way of life and values } \\
\text { Centrality and accessibility }\end{array}$ \\
\hline
\end{tabular}

ates' migration results from four registers of action or logics: utilitarian (labour market), calculating (financial elements), affective (social life) and sensitive (residential amenities).

These logics have been identified on the basis of the various theoretical frameworks found in the literature on internal migration (Table 1). Like Massey et al. (1993), I argue that different theoretical perspectives conceptualize processes on different levels of analysis and cannot be assumed a priori to be inherently incompatible. My argument is that the decision to migrate results from the articulation of these four logics. The way these four logics are combined varies between individuals, according to their aspirations and priorities as well as the trade-offs or compromises they have to make.

\subsubsection{Utilitarian logic}

Factors related to the labour market are, alongside HE, the main driver of internal migration. Two factors related to regional disparities in terms of labour market structure, size and dynamics are identified: current job opportunities and future career possibilities (we discuss the level of salary later). It is therefore necessary to take into account both the short and the long term.

Employment-related factors are even more crucial in the case of young graduates who are entering the labour market and potentially very mobile. Many researchers have highlighted the importance of these factors and the links between spatial and social mobility (Findlay et al., 2009; Haartsen and Thissen, 2014). These researchers have adopted various theoretical perspectives on graduate migration, including determinist and humanist approaches. Determinist approaches see migration as an adjustment between the demand and supply of labour, and sees migrants as subject to external forces. Humanist approaches, however, do not have any preconceptions regarding the importance of the labour market.

\subsubsection{Calculating logic}

The second range of factors are finance related. It may sound artificial, particularly from a neoclassic perspective, to distinguish them from labour market considerations. However, migrants' motivations are of a different nature: utilitarian (to have a job that meets expectations) vs. calculating (maximizing behaviour).

The human capital model of migration (Sjaastad, 1962) sees migration as an individual investment, in which migrants maximize the difference between the benefits and the costs of migration in the short and long term. Migrants are seen as rational actors adjusting to interregional economic disparities, moving if there is net gain to be made; thus young adults are more mobile than older adults, as they are likely to get more return. Another neoclassic author has been influential: Tiebout (1956), who argues that people "vote with their feet" and that individuals move on the basis of a comparison between municipalities offering varying baskets of goods at a variety of prices (tax rates) in order to maximize their personal utility. This has a specific resonance in Switzerland, where tax rates differ considerably between cantons.

\subsubsection{Social logic}

The third range of factors relates to social and affective elements, which also raise the question of the analytical unit (Dieleman, 2001). Historically, migration studies focused on individuals. However, there is rarely a solitary mobile subject; when a person decides to move, he/she takes his/her decision in regard to a specific social context and to his/her ties with others. Thus Mulder (2007) extends the focus to the household and then to the wider family context. An individual's partner plays a central role in his/her migration; as King (2002) states, "love migration" is found in all types of migration. Social factors also include a sense of belonging, or place attachment, which seems particularly important for return migrants (Niedomysl and Amcoff, 2011; Rérat, 2014). Some have argued that spatial rooting is now more influential on career considerations among the upper-middle class (Vincent-Geslin and Kaufmann, 2012). Unlike during the modern period, when social life was subordinated to professional activities, the hierarchy of values has been inverted, or rebalanced, so that professional activities have to be compatible with individuals' life aims (ibid.).

\subsubsection{Sensitive logic}

The fourth logic refers to the quality of life, which may assume a very different meaning for each individual. Rye (2011) observes among young adults that rurality is associated with contradictory images (dull vs. idyllic). Traditionally, research has shown that amenities and quality of life dominate in short-distance moves, but more recently their importance has also been highlighted in amenity-led 
or lifestyle migration toward rural or mountainous regions (Gosnell and Abrams, 2011).

In the case of urban areas, Florida (2004) postulates the prevailing weight of amenities for young creatives (many of whom hold an HE degree, as in the case of the population studied in this paper). He argues that members of the creative class choose to live in urban settings that can be characterized by open-mindedness, tolerance, diversity, cultural activities, etc. Some empirical results show, however, that work-related issues remain the most important (Storper and Scott, 2009), and that amenities are relevant when other requirements (mainly jobs for young people entering the labour market) are met (Niedomysl and Hansen, 2010).

\section{Case study and methodology}

This paper addresses the migration of young university graduates coming from Canton Jura. This Swiss French-speaking region displays the characteristics of a peripheral and rural region in the context of Switzerland ${ }^{2}$. In 2010, there were a total of 70000 inhabitants (ranked 20th out of 26 cantons for number of inhabitants). The region's demographic growth is less dynamic than in the rest of the country (population increase of $2 \%$ vs. $9 \%$ in the whole country between 2000 and 2010; ranked 22nd) and the canton suffers from the depopulation of young people. There is an overrepresentation of the industrial sector ( $42 \%$ vs. $25 \%$; rank 2), and an underrepresentation of the service sector (49\% vs. $71 \%$; rank 26) and of workers with an HE degree (14\% vs. $22 \%$; rank 24).

The target population in this paper is defined as all young people from Canton Jura (whose parents lived in the region when they started university) who graduated between 2000 and 2010 from a "regular" university or a university of applied science ${ }^{3}$. Almost all university graduates had to move to another region, as there is no "regular" university in Jura and the distances make it difficult to commute (see Fig. 1 for the location of HE institutions). Thus they had a first experience of migration on their own, of living in an urban context and of building social ties outside their home region. As two universities of applied science offer some courses in Jura, $8 \%$ of applied science graduates had studied full-time in Jura

\footnotetext{
${ }^{2}$ The meanings of the words "peripheral" and "rural" are highly context dependent and vary between countries.

${ }^{3}$ Studies in regular universities take place after high school. The bachelor lasts 3 years and $90 \%$ of the students go on to do a masters ( 2 years). Universities of applied science - established in the 2000s based on former technical schools - offer vocational education. Their students may have accomplished an apprenticeship or attended a high school; $90 \%$ study to bachelor level. Among young Swiss adults, $15 \%$ get a degree in a university and $13 \%$ in a university of applied sciences. These percentages are higher in Jura (16 and $17 \%$ ). Both types of degree correspond to Level 5A of the International standard classification of education (UNESCO Institute for Statistics, 2012).
}

and $15 \%$ had studied a part of their degree there. Most of the others had to migrate though.

It was not possible to send a survey to a random selection of graduates, as no address lists exist. The snowball sampling method was chosen: 60 of the researcher's acquaintances belonging to the target population were contacted in an email that presented the research and requested the addresses of relevant graduates. When a new address was received, the same message was sent, creating a multiplier effect. An email was also sent to all members of the cantonal administration, and a press conference was organized before Christmas, a period during which most graduates visit their family.

This approach was very successful: 550 emails were received, 1280 individuals identified and 924 people filled in the online questionnaire (response rate of $72 \%$ ), of which 498 had graduated from a regular university and 248 from a university of applied science; these 746 graduates formed the sample addressed here (the remaining were graduates participating in other types of further education). Although snowball sampling is usually used to contact small and hard-toreach populations, it appears to be an effective way of building a large-scale sample in some specific circumstances. The population here is well defined and at ease with information technologies and social networks. Our approach also had the advantage of relying on both strong ties (close friends) and weak ties (acquaintances) (Granoveter, 1973). This erases the effect of spatial distance.

The issue of representivity is important, since biases may occur as individuals do not all have equal probability of being reached through snowball sampling. As there are little official data (OFS, 2010) available, very few comparisons can be made. While no significant differences are found in terms of sex, year of graduation and field of study, university graduates are slightly overrepresented: respondents represent more than $40 \%$ of all graduates from Jura who attended regular universities between 2000 and 2010 and $30 \%$ of graduates from universities of applied science. The propensity to return may be slightly understated since graduates from universities of applied sciences return more often. However, this does not jeopardize the reliability of the sample in respect to the analysis of motivations. Indeed, their motivations are highly correlated $\left(R^{2}=90.2 \%\right)^{4}$.

Graduates were asked about their migration trajectory, profile and motivations. Qualitative information was collected to illustrate and deepen the interpretation of statistical results: plenty of space was given for comments on the questionnaire and 12 in-depth interviews were conducted with

\footnotetext{
${ }^{4}$ Before pooling all those who graduated between 2000 and 2010, I checked that there was no trend over these 10 years (which was the case as the questions explicitly referred to the time when the decision was taken). At the time of the survey, differences were found regarding the barriers to potential return migration. Career and family life gain importance over time (see footnote 8).
} 


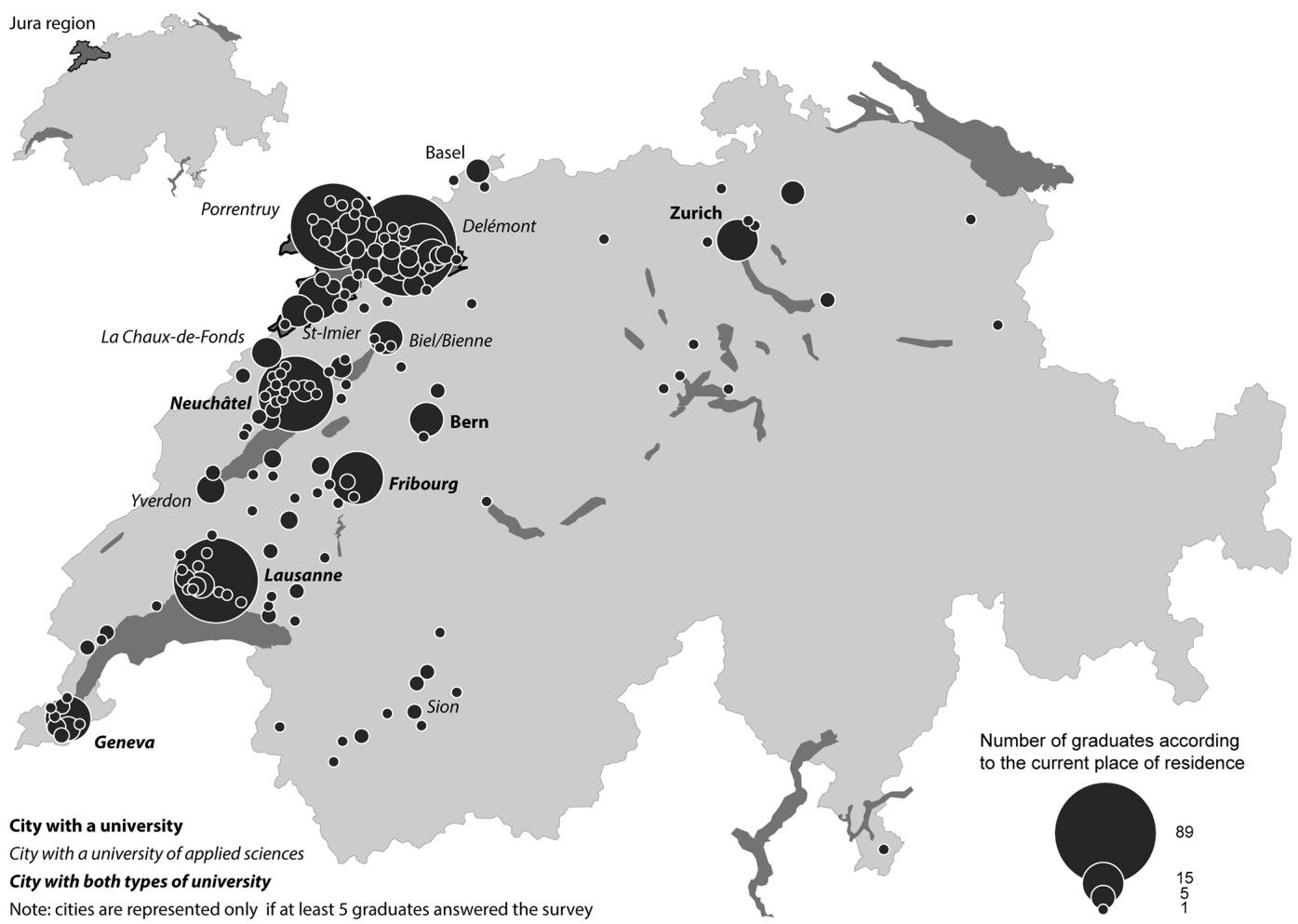

Figure 1. Current place of residence of graduates from Jura (source: questionnaire).

graduates covering a diversity of migration patterns (return and non-return) and profiles (gender and type of degree).

\section{Empirical results}

In this section, the spatial distribution of graduates' places of residence is analysed, and then their self-reported motives for not returning to their home region are considered. A typology is then elaborated which categorizes the graduates according to the factors affecting their migration decision, and qualitative material is used to gain a finer understanding of the migrants' motivations.

\subsection{Young graduates' pattern}

According to the survey, $43.8 \%$ of young people from Jura (327 of the 746 respondents) have returned to live there, which explains the clustering in the northwest of the country (Fig. 1). Although it is difficult to draw a comparison with other case studies (as the share of young adults graduating from HE differs greatly between countries and as research projects differ in terms of geographical and temporal scales and methodology), this loss of young people seems significant, although it is relatively low for a rural region in the global north (Faggian and McCann, 2009; Venhorst, 2013). Some features of Switzerland explain this result. On the one hand, due to the federal organization, administration is de- centralized across the 26 cantons, which guarantees a certain level of job opportunities in the public sector all over the country. On the other hand, the short distances make it possible to reach some urban labour markets even from a peripheral region (see below).

In Jura, regular university graduates are less likely to return than those who studied in a university of applied science ( $40 \%$ vs. $51.6 \%)$. Three factors explain this difference: (1) the latter have vocational training more in line with the needs of the regional labour market, (2) a minority could study in the canton and (3) courses at universities of applied sciences are shorter (see endnote iii).

Non-return graduates live abroad $(4.7 \%)$ and in the rest of Switzerland $(51.5 \%)$. By using an inductive approach to explore the macro perspective, looking at migration patterns in relation with the spatial context, several explanatory factors can be identified. Destinations reveal the attraction of urban centres such as Lausanne, Neuchâtel, Fribourg and Geneva (Fig. 1). However, the geographical distribution of graduates does not strictly reflect the urban hierarchy, and the centreperiphery model appears more complex.

First, language is a major factor. Most migrations remain confined to the French-speaking part, as shown clearly on the map (the regions to the west of a line between Jura, Fribourg and Sion). Few graduates migrate to the big Germanspeaking cities (Zurich, Basel, Bern), and almost none go to the medium-sized ones. This linguistic factor is not spe- 
cific to this population but more general to migration within Switzerland (Schuler et al., 2007).

Second, even within the French-speaking part, the location of graduates does not simply reflect the size of cities. The location of HE institutions plays an important role, since a quarter of graduates remain in the canton where they studied (or $45.5 \%$ of the ones who did not return to Jura) ${ }^{5}$. The distance of the HE institution from Jura is important because the choice of university is partly based on proximity in Switzerland, except for specific fields of study, because HE institutions are decentralized and located in many urban centres. This is exemplified by Neuchâtel, which hosts the closest regular university to Jura and has the biggest cohort of students from Jura. This explains why this city represents the first destination for regular university graduates from Jura, even though its demographic weight (33000 inhabitants) is inferior to that of Geneva (187 000), Lausanne (128000) and even Fribourg (35000).

Finally, the map shows that some graduates have (re)settled near the urban centres. This phenomenon of suburbanization mainly concerns graduates who have a family. Such moves can be interpreted as a consequence of the housing market in core cities (high prices, housing shortage) and of the preference of many families to live in the suburbs (more child-friendly environment, access to home ownership, proximity to nature).

The attraction of urban centres for graduates appears clearly on a macro level. The following part of the analysis adopts a micro perspective, focusing on graduates' motives stated in the questionnaire and interviews.

\subsection{Factors in the decision not to return}

Motivations to settle elsewhere than in Jura are first related to the labour market (Fig. 2) ${ }^{6}$ : two-thirds of graduates say that a job opportunity was very important in their decision and a fifth that it was important. The second criterion refers to career possibilities, i.e. future job opportunities $(30.6 \%$ important and $35 \%$ very important). The third criterion was the graduate's partner, which underlines the importance of the graduates' life course and personal elements ${ }^{7}$.

\footnotetext{
${ }^{5}$ On the whole, almost $70 \%$ of graduates either returned to their home region or stayed in the region where they studied. This confirms that although young graduates are much mobile than average, their migration reflects to a great extent a regional familiarity (Venhorst, 2013).

${ }^{6}$ The question asked was, "What was the importance of the following elements in your decision not to come back to Jura?" Interviewees could choose a response from a five-point Likert scale ("not important at all", "not very important", "moderately important", "important", "very important"). The question regards the time when the decision was taken not to go back to Jura.

${ }^{7}$ This result relates to all graduates, and not all of them lived with a partner when they made the decision ( $35.4 \%$ lived in another kind of household at the time of the survey).
}

Factors seen as (very) important by more than half of the interviewees include the desire for change (32.2 and $25.4 \%$ ), more developed cultural and leisure offerings (29.9 and $22.4 \%$ ), and life in an urban setting (34.5 and $19.3 \%$ ). Also important are accessibility and the desire to get to know another mindset.

Proximity of friends and family, and social activities outside Jura, do not appear as important. This may be explained by the temporary nature of student life in terms of the circle of friends. Financial and economic criteria also seem to be of much less importance. With regard to the level of taxation (which varies greatly between cantons), $4.1 \%$ saw it as important and $0.7 \%$ (i.e. three individuals) as very important ${ }^{8}$.

Graduates were also asked another question, in order to isolate the existence of a job opportunity ("If there was an equivalent job in Jura, would you have come back?"). Even though the notion of an equivalent job is hypothetical, it is interesting to observe that $14.5 \%$ answered "yes" and $30.7 \%$ "probably", while $18.3 \%$ said "no" and $36.4 \%$ "probably not". These results mean that for about $45 \%$ of graduates, the truncated labour market of the home region represents a major constraint preventing a return migration. At the same time, $55 \%$ of them would not have considered settling in Jura. This result highlights the fact that the migration decision is influenced by much more than just work considerations.

It is also interesting to notice that the employmentmigration nexus is not always as straightforward as shown by the places of work of graduates: $72 \%$ of them live and work in the same canton, while the remaining $28 \%$ commute to another canton ${ }^{9}$. For most of them, the choice not to return to Jura may have been justified by job-related reasons; however, it is clear that their place of residence is not always defined by its proximity to their workplace.

\subsection{Typology of migrants according to their motivations}

Differences are found beneath the general trends. In order to get an idea of this diversity, multivariate analyses have been carried out.

A principal component analysis on the importance of the criteria identified four components that explain $62.4 \%$ of the total variance ${ }^{10}$ and whose meaning is revealed by the factor loadings (Table 2). Interestingly, these components correspond to the four logics discussed in the theoretical part:

\footnotetext{
${ }^{8}$ These elements become more important with time. When asked about the importance of factors preventing a return migration at the time of the survey (and not at the time of graduation), $42.5 \%$ mention the circle of friends, $23.9 \%$ their social activities and $34.5 \%$ the level of taxes.

${ }^{9} \mathrm{~A}$ fifth of the graduates who have returned to Jura work in another canton.

${ }^{10}$ PCA was conducted with SPSS on the 12 items (the Likert scale was considered as a continuous scale) with orthogonal rotation (varimax).
} 


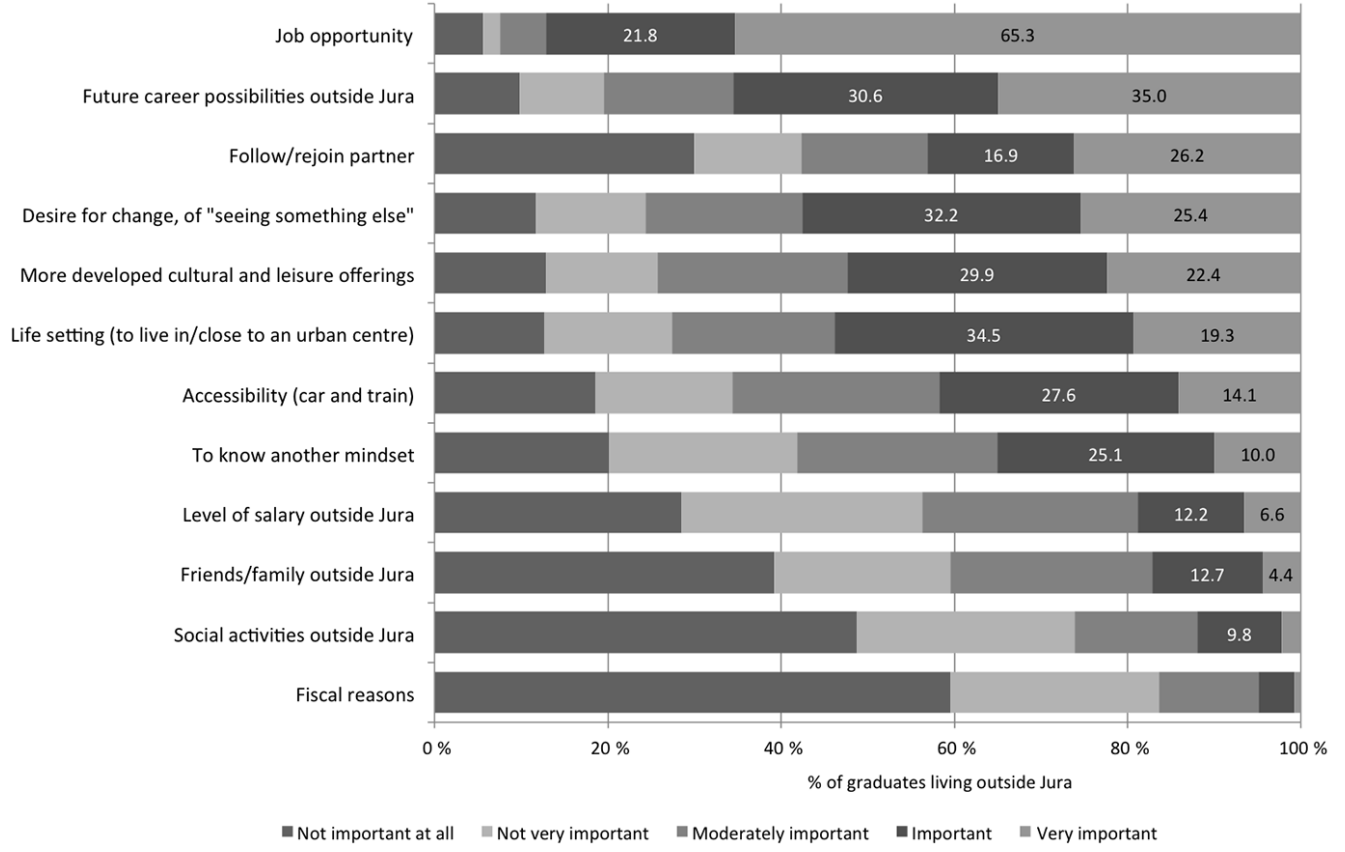

Figure 2. Importance of the motivations not to return to the home region (source: questionnaire).

sensitive, calculating, utilitarian and affective. The term "gradient" highlights the fact that graduates place more or less importance on a component in comparison with their counterparts:

- The urban-rural gradient ( $24.2 \%$ of the total variance) refers to urban amenities and measures the graduates' desire to live in an urban setting.

- The financial gradient (13.4\%) distinguishes graduates according to the relative importance allocated to economic aspects such as salaries and taxes.

- The work/career gradient $(12.6 \%)$ brings into opposition graduates who place importance on the labour market (present and future job opportunities) with those whose migration behaviour is explained by their partner.

- The social ties gradient (12.2\%) measures the degree with which graduates value the proximity of friends and social activities. This component is also positively correlated to the desire to follow their partner ${ }^{11}$.

\footnotetext{
${ }^{11}$ The fact that the item "partner" is correlated with two axes shows the existence of two logics. Some graduates follow/re-join their partner, potentially to the detriment of their professional life, while some others may stay in the region where they studied and where the partner lives. They correspond, respectively, to the types 2 and 5 in the typology presented below.
}

Each graduate was characterized by a factor loading on each component. On this basis, a hierarchical cluster analysis (Ward's logarithm) was conducted to establish a typology. The number of groups (six) was chosen by examining the dendrogram and the scree plot. Table 3 shows the average factor loadings for the individuals in each group; a value below zero does not mean that the factor is not important in absolute terms but that it is less important in relative terms, i.e. in comparison with the other interviewees. Interview responses and comments left in the survey have been used to deepen the understanding of how factors are combined in the migration decision.

The first group (13.9\% of non-returning graduates) is labelled "job opportunists". These graduates were more likely than others to leave for financial or work-related issues. The transition to the labour market may be either a push factor (the lack of opportunities in Jura) or a pull factor (the existence of opportunities elsewhere). The labour market represents a constraint experienced in various ways. For some, not being able to find a job in Jura was anticipated and accepted ("It has never bothered me"), while some others saw it as a sacrifice ("I had no other choice but to be expatriated"). In the latter case, the labour market clearly represents a determinant structural constraint. The decision not to go back to Jura was motivated neither by the residential context nor by a rejection of rurality.

The second group $(19.7 \%)$ has negative scores on all axes, which shows that their migration was in most cases the consequence of constraints. They are "constrained and pragmatic" migrants, since their choice to leave Jura seems to 
Table 2. Summary of the factor analysis results for the motivations of not returning to the home region (only factor loadings above 0.3 are indicated) (source: questionnaire).

\begin{tabular}{|c|c|c|c|c|}
\hline \multirow[b]{2}{*}{ Items } & \multicolumn{4}{|c|}{ Rotated factor loadings } \\
\hline & $\begin{array}{l}\text { Component 1: } \\
\text { urban-rural gradient }\end{array}$ & $\begin{array}{r}\text { Component 2: } \\
\text { financial gradient }\end{array}$ & $\begin{array}{r}\text { Component 3: } \\
\text { work/career gradient }\end{array}$ & $\begin{array}{r}\text { Component } 4 \text { : } \\
\text { social ties gradient }\end{array}$ \\
\hline Job opportunity & & & 0.84 & \\
\hline Future career possibilities & & & 0.71 & \\
\hline Level of salary & & 0.78 & & \\
\hline Follow or re-join partner & & & -0.40 & 0.38 \\
\hline $\begin{array}{l}\text { Proximity of friends and } \\
\text { family outside Jura }\end{array}$ & & & & 0.79 \\
\hline Social activities & & & & 0.72 \\
\hline $\begin{array}{l}\text { Desire for change, to "see } \\
\text { something else" }\end{array}$ & 0.76 & & & \\
\hline $\begin{array}{l}\text { Living environment } \\
\text { (in/close to an urban centre) }\end{array}$ & 0.81 & & & \\
\hline $\begin{array}{l}\text { More developed cultural } \\
\text { and leisure offerings }\end{array}$ & 0.82 & & & \\
\hline To know another mindset & 0.77 & & & \\
\hline Accessibility (car and train) & 0.5 & & & \\
\hline Fiscal reasons & & 0.85 & & \\
\hline
\end{tabular}

Table 3. Average factor loadings according to the six types of graduates (source: questionnaire).

\begin{tabular}{lrrrrr}
\hline Types & Proportions & $\begin{array}{r}\text { Component 1 } \\
\text { (urban-rural) }\end{array}$ & $\begin{array}{r}\text { Component 2 } \\
\text { (financial elements) }\end{array}$ & $\begin{array}{r}\text { Component 3 } \\
\text { (work/career) }\end{array}$ & $\begin{array}{r}\text { Component 4 } \\
\text { (social ties) }\end{array}$ \\
\hline Type 1: Job opportunists & $13.9 \%$ & -0.71 & 1.40 & 0.19 & -0.01 \\
Type 2: Constrained and pragmatic & $19.7 \%$ & -1.11 & -0.36 & -0.11 & -0.57 \\
Type 3: Convinced migrants & $17.8 \%$ & 0.66 & 0.93 & 0.33 & 0.17 \\
Type 4: Urban seekers & $20 \%$ & 0.90 & -0.57 & -0.11 & -0.70 \\
Type 5: Rooted city-dwellers & $24.1 \%$ & 0.07 & -0.68 & 0.39 & 0.92 \\
Type 6: Others & $4.6 \%$ & 0.07 & -0.26 & -2.95 & 0.03 \\
\hline
\end{tabular}

be the result of a decision to follow their partner. For these graduates, negotiations with their partner or the existence of a better job opportunity for the partner outside Jura may have led them to give up on a return migration:

I am always asking myself "If my boyfriend did not come from [the German-speaking part], if I had been single, what would I have done?" I think that I would have considered differently the job offer I refused in Jura [...] But frankly, love, that plays a big role! (Interview)

For the third group (17.8\%), out-migration resulted from the convergence of all criteria. These "convinced migrants" put more weight than average on residential context, financial elements, work/career and social ties:

Working full-time and having taken roots in Lausanne due to my associative involvement, it is hard to imagine returning to Jura even if I go there regularly [...] Moreover, most of my friends here are “exiles” like me! (Survey)

The fourth group $(20 \%)$ corresponds to the "urban seekers". Some have pointed out sensitive factors related to the living environment (see the terms "taste" and "affinity" in the following quotation) and to the attractiveness of urban centres ("dynamic") in regard to rural regions ("too quiet"): 
It is a matter of affinity, of taste. I like the big cities. Jura is a rural region with all that goes with that: few inhabitants, few opportunities for work in my field, little anonymity ... And nothing could really change that. (Interview)

I'm more of a town mouse than a country mouse! I have always liked the city more than the countryside. I would not like to live in the countryside near Lausanne either... (Survey)

In contrast, they assigned a below-average score to the other components - especially social ties. This may be explained by the fact that less of them were part of a couple than the others and that some of them settled in another region than the one in which they studied.

The fifth group $(24.1 \%)$ is called the "rooted citydwellers". Financial elements have an even weaker importance for them, while living in an urban setting was a little more important than average. It would, however, be erroneous to minimize the importance of this factor, as more than two-thirds of these graduates live in an urban centre (vs. $57.1 \%$ of all graduates). It rather seems that a job opportunity enables them to enter the labour market in the region where they studied and are already socially integrated. Many of these graduates actually highlighted the role of social ties:

Would I have come back? Well, that's difficult to say ... I didn't exclude it but the distance from my circle of friends would certainly have tipped the scales against it... (Interview)

Despite the small size of the sixth and final group (4.6\%), a certain level of heterogeneity is observed. These graduates may be working in Jura without living there, or working in a self-employed capacity or active all over the country.

The probability of a return migration in case of an equivalent job reveals the level of constraints represented by the job market (Fig. 3). This is specifically the case for the constrained and pragmatic migrants $(71.3 \%$ would have considered returning) and the job opportunists (60\%). In contrast, about a fourth of urban seekers and a third of convinced migrants would not consider returning to Jura for an equivalent job. For them, other dimensions such as social and sensitive factors made the difference.

The differences between the six types are also highlighted by using the Faggian et al. (2006) distinction between "university stayers" (graduates who have stayed in the canton where they attended university; 45.5\%) and "repeat migrants" (graduates who moved further to another region; $54.5 \%)$. A majority of rooted city-dwellers $(63.1 \%)$ and convinced migrants $(52.6 \%)$ are university stayers, which confirms the importance of the social network and the urban setting. Two-thirds of the urban seekers moved to another region, which is coherent with their factor loadings (the highest for the urban/rural component and the lowest for the social component). Job opportunists and constrained/pragmatic migrants are the groups for which job-related reasons prevented a return to Jura and they also more mobile than average after graduation (74.2 and 61.9\%). Finally, the sixth group appears once again to have a distinct behaviour (only $14.3 \%$ did not move further).

\section{Conclusion}

This paper addresses the uneven geography of educationinduced migration in the case of young adults from a Swiss rural region. A majority of them do not return after graduation $(54 \%)$, a result in accordance with many studies, which highlight the imbalance between rural and metropolitan regions. Based on a questionnaire and interviews, the paper explains the reasons why some graduates decide not to return and sheds light on the transition from HE into the labour market.

On a macro-analytical scale (spaces), graduates' destinations reveal the regional disparities in terms of labour market and the attraction of urban regions. Two elements related to the Swiss context make this urban-rural gradient more complex: language (migration remains mostly confined to the French-speaking regions) and the location of universities (45\% of the graduates who do not return to their home region stay where they studied).

On the micro scale (individuals), the urban-rural gradient has two implications. Self-evidently, it means disparities for graduates in terms of job opportunities. Furthermore, the location of universities in urban centres outside Jura implies that almost all graduates had to move to study. This first independent migration is the beginning of a distancing from the place of origin and implies the building of new social ties and the experience of a new residential context. In other words, "migrating to learn" also involves becoming familiar with another region for young adults (Venhorst, 2013).

We also argue for the need to overcome determinist approaches (which apply a rational or pre-defined behaviour to individuals) and to adopt a humanist approach that takes into account self-reported motivations. We have identified four registers of action based on the mechanisms highlighted by the main paradigms in migration research: factors related to the labour market (utilitarian), to social life (affective), to residential amenities (sensitive) or to financial nature (calculating).

Job-related factors are the most important criteria in the graduates' decision not to return to their rural home region, but they only partially explain the loss recorded by Jura. Young graduates' migration is more than an adjustment variable between labour demand and supply: $55 \%$ of graduates would not have returned even for an equivalent job. Moreover, $28 \%$ live in one canton and work in another one. For them, commuting (a reversible form of mobility that makes it possible to keep the same friend circle and living environ- 


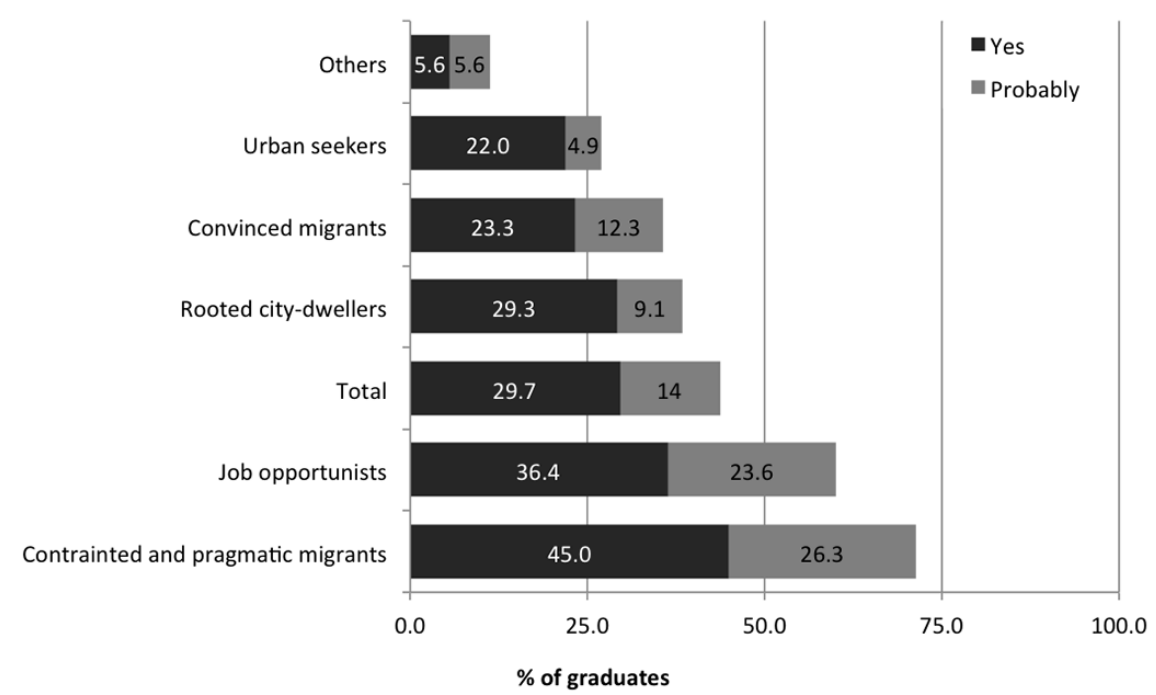

Figure 3. Probability of a return migration in the case of an equivalent job (source: questionnaire).

ment) replaces a further migration (Vincent-Geslin and Kaufmann, 2012).

Criteria related to social life - especially the proximity of the partner - and to place attachment play an important role: one quarter of graduates remain in the region where they studied. Social activities and the circle of friends, however, appear less central than in return migration (Niedomysl and Amcoff, 2011; Rérat, 2014). This may be due to the many changes that go with this transition: fellow students may go back to their home region, go to another region or stay in the city of study.

The impact of residential amenities is also to be noted. They are important but not dominant, as Florida (2004) postulates for young creatives. They influence graduates' migration decisions in combination with work and personal reasons. This confirms the interpretation that amenities are relevant when some other factors (job, partner's aspirations) are fulfilled (Niedomysl and Hansen, 2011). Moreover, the attractiveness of central areas and urban amenities seems to decrease over the life course in favour of the suburbs.

It is interesting to note that the calculating logic is clearly less important than the others for young graduates. If workrelated issues are central, strictly economic and financial elements (salary and taxes) play a negligible role in the decision-making process.

Migration motivations are not only multidimensional and complex but they are diverse in the sense that differences are found even within a seemingly homogeneous population group. This is shown by the existence of five main types of migrants ("constrained and pragmatic migrants", "job opportunists", "rooted-city dwellers", "convinced migrants", "urban seekers"). The importance of, and the articulation and trade-offs between, the four logics vary among these groups.
In addition to a deeper understanding of the transition from HE to the labour market and its spatial patterns, our results highlight two important principles in migration studies. First, there is a need to combine macro and micro approaches and to complete determinist approaches with a humanist view by investigating self-reported motives. Second, migration decisions cannot be reduced to a single dimension but refer to the combination of four logics (utilitarian, calculating, affective and sensitive), which differs between population groups. This paper calls for further studies to test this approach on other population groups (less is known, for example, about young adults who do not take part in HE) and in other spatial contexts (e.g. graduates coming from urban areas).

The migration of young graduates is a major issue for rural areas. Regional policies traditionally aim at the creation of highly qualified jobs to attract or retain them. They would meet a certain amount of success $(45 \%$ of the graduates in the survey would have returned for an equivalent job opportunity) but are limited in scope (55\% would not have done so). Given this limitation, a new kind of instrument is emerging: the regional social network (Rérat, 2013; Rérat and Jeannerat, 2014). This approach to policymaking no longer considers highly qualified people leaving a region as a loss but as potential resources to be mobilized and capitalized at a distance through various forms of network. This instrument is still rather new and it is difficult to assess its efficiency. It seems, however, to be an interesting direction to explore in a context of growing mobilities and use of e-technologies. 


\section{Data availability}

Data are not publicly accessible due to the protection of personal data and privacy. The researcher made the commitment to interviewees that the data would be anonymously and confidentially analysed and interpreted.

Acknowledgements. The author is grateful to the institutions that supported this research project: the Anne and Robert Bloch Foundation (FARB), the Canton of Jura, the University of Neuchâtel and regiosuisse.

Edited by: M. Houssay-Holzschuch

Reviewed by: two anonymous referees

\section{References}

Beck, U.: Risk Society: Towards a New Modernity, Sage, London, 272 pp., 1992.

Boltanski, L. and Thévenot, L.: On Justification. The Economies of Worth, Princeton University Press, Princeton, 400 pp., 2006.

Boyle, P., Halfacree, K., and Robinson, V.: Exploring Contemporary Migration, Longman, Essex, 282 pp., 1998.

Corcoran, J., Faggian, A., and McCann, P.: Human Capital in Remote and Rural Australia: The Role of Graduate Migration, Growth Change, 41, 192-229, 2010.

DaVanzo, J.: Differences between Return and Nonreturn Migration: An Econometric Analysis, Int. Migr. Rev., 10, 13-27, 1976.

Dieleman, F. M.: Modelling residential mobility: A Review of Recent Trends in Research, Journal of Housing and the Built Environment, 16, 249-265, 2001.

Dubet, F.: Sociologie de l'expérience, Seuil, Paris, 288 pp., 1994.

Faggian, A. and McCann, P.: Universities, Agglomerations and Graduate Human Capital Mobility, Tijdschr. Econ. Soc. Ge., 100, 210-223, 2009.

Faggian, A., McCann, P., and Sheppard, S.: An Analysis of Ethnic Differences in UK Graduate Migration Behaviour, Ann. Regional Sci., 40, 461-471, 2006.

Fielding, A.: Migration and Culture, in: Migration Processes and Patterns, edited by: Champion, A. and Fielding, A., Belhaven, London, 201-212, 1992.

Findlay, A., Mason, C., Houston, D., McCollum, D., and Harrison, R.: Escalators, Elevators and Travelators: The Occupational Mobility of Migrants to Southeast England, J. Ethn. Migr. Stud., 35, 861-879, 2009.

Florida, R.: The Rise of the Creative Class: And How it's Transforming Work, Leisure, Community and Everyday Life, Basic Books, New York, 434 pp., 2004.

Glaeser, E. L. and Maré, D. C.: Cities and Skills, J. Labor. Econ., 19, 316-342, 2001.

Gordon, I.: Migration in a Segmented Labour Market, T. I. Brit. Geogr., 20, 139-155, 1995.

Gosnell, H. and Abrams, J.: Amenity Migration: Diverse Conceptualizations of Drivers, Socioeconomic Dimensions, and Emerging Challenges, GeoJournal, 76, 303-322, 2011.

Granoveter, M. S.: The Strength of Weak Ties, Am. J. Sociol., 78, 1360-1380, 1973.
Haartsen, T. and Thissen, T.: The Success-Failure Dichotomy Revisited: Young Adults' Motives to Return to their Rural Home Region, Children's Geographies, 12, 87-101, 2014.

Halfacree, K.: A Utopian Imagination in Migration's Terra Incognita? Acknowledging the Non-Economic Worlds of Migration Decision-Making, Popul. Space Place, 10, 239-253, 2004.

Jeffrey, C.: Geographies of Children and Youth I: Eroding Maps of Life, Prog. Hum. Geog., 34, 495-505, 2010.

King, R.: Towards a New Map of European Migration, International Journal of Population Geography, 8, 89-106, 2002.

Lahire, B.: The Plural Actor, Polity, Cambridge: Polity, 280 pp. 2010.

Lundholm, E.: Interregional Migration Propensity and Labour Market Size in Sweden 1970-2001, Reg. Stud., 44, 455-464, 2010.

Massey, D. S., Arango, J., Hugo, G., Kouaouci, A., Pellegrino, A., and Taylor, E. J.: Theories of International Migration: A Review and Appraisal, Popul. Dev. Rev., 19, 431-466, 1993.

Mulder, C. H.: The Family Context and Residential Choice: A Challenge for New Research, Popul. Space Place, 13, 265-278, 2007.

Niedomysl, T. and Amcoff, J.: Why Return Migrants Return: Survey Evidence on Motives for Internal Return Migration in Sweden, Popul. Space Place, 17, 656-673, 2011.

Niedomysl, T. and Hansen, H. K.: What Matters More for the Decision to Move: Jobs versus Amenities, Environ. Plann. A, 42, 1636-1649, 2010.

OFS: Etudiants et examens finals des hautes écoles, Office fédéral de la statistique, Neuchâtel, available at: $\quad$ https://www.bfs.admin.ch/bfs/fr/home/statistiques/ education-science/diplomes/degre-tertiaire-hautes-ecoles.html (last access: 18 October 2016), 2010.

Pattaroni, L., Thomas, M.-P., and Kaufmann, V.: Habitat urbain durable pour les familles, LASUR-EPFL, Lausanne, 75 pp., 2009.

Ravenstein, E. G.: The laws of migration, J. R. Stat. Soc., 52, 214 301, 1889.

Rérat, P.: Après le diplôme. Les parcours migratoires au sortir des hautes écoles, Alphil-Presses universitaires suisses, Neuchâtel, 294 pp., 2013.

Rérat, P.: Highly qualified rural youth: Why do young graduates return to their home region?, Children's Geographies, 12, 70-86, 2014.

Rérat, P. and Jeannerat, H.: Peripheries, Mobilities and ETechnologies: The Rise of Regional Social Network Policies, disP The Planning Review, 196, 33-42, 2014.

Rye, J. F.: Youth Migration, Rurality and Class: A Bourdieusian Approach, Eur. Urban Reg. Stud., 18, 170-183, 2011.

Schuler, M., Dessemontet, P., Jemelin, C., Jarne, A., Pasche, N., and Haug, W.: Atlas des mutations spatiales de la Suisse, NZZ, Zurich, 416 pp., 2007.

Sjaastad, L. A.: The Costs and Returns of Human Migration, J. Polit. Eco., 70, 80-93, 1962.

Smith, D. P., Rérat, P., and Sage, J.: Youth migration and spaces of education, Children's Geographies, 12, 1-8, 2014.

Smith, D. P. and Sage, J.: The Regional Migration of Young Adults in England and Wales (2002-08): A 'Conveyor-Belt' of Population Redistribution?, Children's Geographies, 12, 102-117, 2014. 
Storper, M. and Scott, A. J.: Rethinking Human Capital, Creativity and Urban Growth, J. Econ. Geogr., 9, 147-167, 2009.

Tiebout, C. M.: A Pure Theory of Local Expenditures, J. Polit. Eco., 64, 416-424, 1956.

UNESCO Institute for Statistics: International standard classification of education, UNESCO, Montreal, 2012.
Venhorst, V. A.: Graduate Migration and Regional Familiarity, Tijdschr. Econ. Soc. Ge., 104, 109-119, 2013.

Vincent-Geslin, S. and Kaufmann, V.: Mobilité sans racines. Plus loin, plus vite... plus mobiles?, Descartes, Paris, 142 pp., 2012.

Zelinsky, W.: The Hypothesis of the Mobility Transition, Geogr. Rev., 61, 219-249, 1971. 